Disponível em:

http://editora.unoesc.edu.br/index.php/race

RACE, Joaçaba, v. 17, n. 1, p. 55-78, jan./abr. 2018

\title{
ANÁLISE DAS INFORMAÇÕES AMBIENTAIS EVIDENCIADAS NOS RELATÓRIOS DE SUSTENTABILIDADE E RELATÓRIOS ANUAIS SOBRE EFLUENTES LÍQUIDOS DAS EMPRESAS BRASILEIRAS
}

\author{
Analysis of environmental information evidenced in Sustainability Reporting and Annual \\ Reports on liquid effluent of Brazilian companies
}

Mara Vogt

E-mail: maravogtcco@gmail.com

Mestre em Ciências Contábeis pela Universidade Regional de Blumenau; Bacharel em Ciências Contábeis pela Sociedade Educacional FAI Faculdades de Itapiranga; Doutoranda em Ciências Contábeis e Administração pela Universidade Regional de Blumenau; Bolsista Capes na Universidade Regional de Blumenau.

Larissa Degenhart E-mail: lari_ipo@hotmail.com Mestre em Ciências Contábeis pela Universidade Regional de Blumenau; Bacharel em Ciências Contábeis pela Sociedade Educacional FAI Faculdades de Itapiranga; Doutoranda em Ciências Contábeis e Administração pela Universidade Regional de Blumenau; Bolsista na Universidade Regional de Blumenau. Endereço para contato: Rua Antônio da Veiga, 140, sala D-202, - Bairro: Itoupava Seca, CEP: 89030-903, Blumenau-, Santa Catarina, Brasil.

Nelson Hein

E-mail: hein@furb.br Pós-doutor pela Associação Instituto Nacional de Matemática Pura e Aplicada e pela Anderson School of Management da Universidade do Novo México (EUA); Doutor em Engenharia de Produção pela Universidade Federal de Santa Catarina; Professor no Departamento de Matemática da Universidade Regional de Blumenau.

Fabricia Silva da Rosa

E-mail: fabriciasrosa@hotmail.com

Pós-doutora em Contabilidade pela Universidade Federal de Santa Catarina; Doutora em Contabilidade pela Universidad de Valéncia; Doutora em Engenharia de Produção pela Universidade Federal de Santa Catarina; Professora no Programa de Pós-graduação em Contabilidade e Administração da Universidade Federal de Santa Catarina. 
Resumo

Neste estudo objetivou-se analisar as informações ambientais evidenciadas nos Relatórios de Sustentabilidade (RS) e Relatórios Anuais (RA) sobre efluentes líquidos das empresas brasileiras. Realizou-se pesquisa descritiva, documental e quantitativa. A população da pesquisa compreende as 100 empresas pertencentes ao Índice Brasil 100 e a amostra foi composta por 97 dessas empresas. Foram verificados critérios e subcritérios com diferentes escalas sobre o aspecto efluentes nos RA e RS no período de 2010 a 2013. Calculou-se o peso da informação por meio da entropia e após foi aplicado o método Simple Additive Weighting (SAW) para a elaboração dos rankings e a correlação de Spearman. Em relação aos critérios e subcritérios analisados, o tipo de informação apresentou a maior influência na evidenciação sobre efluentes em ambos os relatórios. No que se refere ao ranking geral sobre as informações ambientais verificadas nos RA, as empresas que mais se destacaram foram a BRF - Brasil Foods e a Duratex. Já referente às informações divulgadas nos RS, as empresas Fibria e BRF - Brasil Foods foram destaque no período analisado. Conclui-se que as empresas brasileiras deveriam divulgar mais informações ambientais sobre efluentes em seus relatórios, visto que muitas destas não apresentaram informações sobre os critérios e subcritérios analisados.

Palavras-chave: Evidenciação ambiental. Efluentes líquidos. Empresas brasileiras.

\section{Abstract}

This study aimed to analyze the environmental information reported through Sustainability Reports (RS) and Annual Reports (RA) on wastewater of Brazilian companies. A descriptive, document and quantitative research. The study population includes 100 companies belonging to the Brazil Index 100 and the sample was composed of 97 of these companies. Criteria and sub-criteria were verified with different scales on the aspect effluents in RA and RS for the period 2010 to 2013. We calculated the weight of the information through the entropy and after we applied the method Simple Additive Weighting (SAW) for the development the rankings and the Spearman correlation. Regarding the analyzed criteria and sub-criteria, the type of information had the highest influence on the disclosure of effluent in both reports. Regarding the overall ranking on environmental information verified in $R A$, companies that stood out were the BRF - Brazil Foods and Duratex. Already regarding the information disclosed in the $R S$, the Fibria companies and BRF - Brazil Foods were highlighted during the period. It is concluded that Brazilian companies should disclose more environmental information effluents in their reports, as many of these have not provided information on the criteria and sub-criteria analysis.

Keywords: Environmental disclosure. Wastewater. Brazilian companies. 


\section{INTRODUÇÃO}

O aquecimento global, juntamente com as mudanças climáticas, têm sido o problema ambiental mais desafiador que o mundo está enfrentando, e esse problema afetará o futuro do Planeta (NOR et al., 2016). Diante disso, há uma pressão constante da sociedade para um ambiente melhor, reforçando o papel da divulgação ambiental na diminuição da poluição (TIAN et al., 2016).

Além disso, a atenção e a pressão da sociedade em relação aos problemas ambientais podem exigir que o Governo destine maiores recursos para o controle da poluição (ZHENG; KAHN, 2013) e que criem cada vez mais regulamentações ambientais (NOR et al., 2016). Em resposta a essas preocupações públicas, diante da falta de transparência das empresas houve uma tendência maior de estas divulgarem relatórios de sustentabilidade (BRAAM et al., 2016).

Contudo, é notável que as empresas que normalmente divulgam mais informações sobre a poluição são aquelas que apresentam menores níveis de poluição no meio ambiente, além de terem mais investimentos em controle da poluição, resultando na eficácia da divulgação ambiental com vistas ao controle dessa poluição (TIAN et al., 2016).

Nos últimos 15 anos as empresas aumentaram bastante a sua evidenciação ambiental em relação à sua estratégia ambiental, como resposta às pressões institucionais (ALBERTINI, 2013). Ainda para a autora, durante os últimos 30 anos, o impacto ambiental das atividades das organizações tornou-se cada vez mais preocupante entre os grupos ambientalistas, legisladores, clientes, sociedade, e, ainda, autoridades públicas. A demanda para um ambiente mais limpo acabou forçando as empresas a empreenderem e participarem de programas de prevenção da poluição. Da mesma forma, Qian e Schaltegger (2017) destacam que os pesquisadores na área contábil têm debatido e investigado a evidenciação ambiental principalmente nas últimas décadas.

Especificamente sobre água, energia, biodiversidade, emissões, efluentes, resíduos, impactos e transporte, Rosa et al. (2014) frisam que o interesse dos pesquisadores sobre esses aspectos relacionados ao desempenho ambiental tem aumentado consideravelmente nos últimos anos. Deve-se considerar que cada empresa possui particularidades, pois os impactos estão diretamente relacionados às atividades e, tanto as leis quanto as diretrizes sobre a evidenciação ambiental podem ser diferentes de um país para o outro.

Diante do exposto anteriormente e em razão da importância dos efluentes líquidos no meio ambiente, nota-se que por mais que haja o interesse dos pesquisadores 
sobre esses aspectos, poucos estudos têm analisado as informações específicas sobre efluentes líquidos, ainda mais quando se trata do cenário nacional, o que demonstra que existe uma lacuna importante que precisa ser explorada.

Nesse sentido, destaca-se a seguinte questão que norteia esta pesquisa: quais as informações ambientais evidenciadas nos Relatórios de Sustentabilidade e Relatórios Anuais sobre efluentes líquidos das empresas brasileiras listadas no IBrX-100 da BM\&FBovespa? No intuito de responder a essa questão, o objetivo com este estudo consiste em analisar as informações ambientais evidenciadas nos Relatórios de Sustentabilidade e Relatórios Anuais sobre efluentes líquidos das empresas brasileiras listadas no IBrX-100 da BM\&FBovespa.

O estudo justifica-se conforme Rosa, Ensslin e Ensslin (2009), pois se percebe grande movimentação social e científica em relação às questões ambientais e ao comportamento das empresas sobre o assunto. Desse modo, a ciência discute de que forma as organizações devem passar a evidenciar as informações de cunho ambiental. Assim, diversas pesquisas vêm sendo realizadas com o intuito de promover a avaliação de desempenho das informações ambientais divulgadas, isto é, o denominado environmental disclosure.

O estudo possui relevância e contribui com a literatura, pois poucos estudos têm analisado a evidenciação ambiental sobre efluentes líquidos no contexto nacional e internacional. Além disso, tendo em vista a importância da evidenciação ambiental no âmbito mundial e seus benefícios para as empresas que evidenciam, bem como para a sociedade e meio ambiente, entende-se que será possível identificar diversas informações importantes no que se refere aos efluentes líquidos a partir desta pesquisa.

\section{EVIDENCIAÇÃO AMBIENTAL}

A evidenciação ambiental corporativa é entendida como um conjunto de informações relacionadas às atividades de uma empresa em prol do meio ambiente. $\mathrm{O}$ desempenho dessas organizações, bem como as implicações financeiras, expandiram nos últimos anos de maneira significativa em todo o mundo (WANG; BERNELL, 2013).

Para Said, Omar e Abdullah (2013), a evidenciação ambiental demonstra se as atividades da empresa possuem impacto sobre o meio ambiente, incluindo o cumprimento das leis ambientais, dos regulamentos e das políticas, a proteção do meio ambiente e a conservação dos recursos naturais entre outros fatos. Quanto mais a em- 
presa for participar em atividades ambientais, maior será sua divulgação ou o relato de suas atividades em favor do meio ambiente (SAID; OMAR; ABDULLAH, 2013).

Para tanto, as empresas utilizam a evidenciação ambiental como forma de divulgar os aspectos, assim como os impactos ambientais (ROSA et al., 2011; ROSA et al., 2012). Diante da preocupação da sociedade com a natureza, as empresas são pressionadas a divulgar informações que auxiliem as partes interessadas na avaliação do seu relacionamento com o meio ambiente, ou seja, prestam contas à sociedade (ROSA et al.; ROSA et al., 2011). Da mesma forma, Aburaya (2012) salienta que a crescente preocupação mundial com o meio ambiente faz com que aumentem as informações às partes interessadas.

Conforme Oliveira, Machado e Beuren (2012), a evidenciação das ações relacionadas à responsabilidade social e sustentabilidade empresarial é essencial, contudo, na legislação brasileira não há nada que obrigue as empresas a divulgarem. Por mais que não seja obrigatória, a divulgação ambiental de forma voluntária e transparente aumenta ainda mais o valor da empresa, pois demonstra que esta faz questão de divulgar tais informações (CLARKSON et al., 2013), tornando-se uma fonte potencial de informações de desempenho ambiental (CHO; PATTEN, 2013).

Contudo, vale ressaltar que essa divulgação voluntária pode ser vista de diferentes formas pelos interessados (PEREIRA; MORAIS LUZ; CARVALHO, 2015), e, por conta disso, está em constante debate em âmbito mundial (NOR et al., 2016).

Assim, os relatórios ambientais são documentos emitidos por organizações que possuem o objetivo de se comunicar com as partes interessadas, no que diz respeito às questões ambientais mais relevantes. Mesmo que os relatórios sejam uma prática sempre mais importante, a qualidade e o tipo de informações coletadas nesses relatórios nem sempre são satisfatórios (SAID; OMAR; ABDULLAH, 2013).

Por mais que existam diversas iniciativas para a sustentabilidade das empresas visando impressionar as partes interessadas, os custos envolvidos nesse processo podem limitar a sua realização (IATRIDIS, 2013). Entretanto, as empresas buscam, de alguma maneira, evidenciar os atos e fatos oriundos de suas atividades, até porque há pressões das partes interessadas. Dessa forma, as empresas acabam adotando práticas para restabelecer e preservar o meio ambiente, buscando, assim, a conservação de recursos naturais para as gerações futuras (BEUREN; NASCIMENTO; ROCHA, 2013). Essas pressões das partes interessadas fizeram com que as empresas utilizassem cada vez mais as estruturas de divulgação, ou seja, as diretrizes do Global Reporting Initiative (GRI) para divulgarem informações sobre o meio ambiente (VILLIERS; LOW; SAMKIN, 2014). 
Rosa et al. (2014) salientam que a evidenciação ambiental pode ser conceituada como um meio ou então um conjunto de meios que é utilizado por diferentes empresas para expor aos seus stakeholders suas práticas ambientais e, ao mesmo tempo, serve como ferramenta de tomada de decisões para os interessados nessas informações. Para Lu e Abeysekera (2014), a divulgação social e ambiental é considerada um diálogo entre as empresas e os seus stakeholders, estes interessados em atividades sociais e ambientais das empresas, estas evidenciadas por meio de relatórios de sustentabilidade (LU; ABEYSEKERA, 2014).

Quanto menor for o desempenho ambiental das empresas, maiores serão as pressões políticas e sociais que estas enfrentam e que ameaçam sua legitimidade (MENG et al., 2014). É por conta disso que a evidenciação ambiental pode ser utilizada como uma estratégia para comunicar a capacidade real da empresa e seu desempenho (MENG et al., 2014). Assim, além de a evidenciação aumentar a transparência das empresas, contribui para que estas sejam reconhecidas como mais responsáveis (MACÊDO et al., 2014).

A transparência ambiental das empresas ganhou destaque nacional e internacional como resposta às demandas da sociedade relacionadas ao consumo de recursos naturais e impactos ambientais causados pelas empresas em razão das atividades que desenvolvem e seus efeitos sobre o clima, a biodiversidade e, ainda, a saúde humana (ROSA et al., 2015). A comunidade científica reconhece a relevância de se avaliar o nível de evidenciação ambiental das empresas, com vistas a contribuir para o desenvolvimento sustentável (ROSA et al., 2015).

A evidenciação ambiental pode ser utilizada como estratégia de legitimidade corporativa, exercendo um papel importante para que as empresas e a sociedade tomem conhecimento e promovam a melhoria da sustentabilidade (ROSA et al., 2015). Nesse sentido, os autores ressaltam que a evidenciação é considerada um conjunto de meios utilizados pelas empresas para demonstrar à sociedade como são gerenciados os impactos causados ao meio ambiente por meio de suas atividades.

Em razão do fato de as empresas serem cada vez mais responsabilizadas pelo impacto de suas ações sobre o meio ambiente, isso gera uma maior tendência de divulgarem informações ambientais em relatórios de sustentabilidade e anuais (BRAAM et al., 2016). Dessa maneira, a conscientização criada por meio da evidenciação ambiental pressionou as empresas para que forneçam informações relacionadas às atividades desenvolvidas para atender às expectativas das partes interessadas (MATHUVA; KIWEU, 2016). 
Nesse sentido, a divulgação de informações de cunho social e ambiental serve como um meio para estabelecer e melhorar a legitimidade das empresas, por meio de suas atividades que são relacionadas aos funcionários, clientes, sociedade e meio ambiente (MATHUVA; KIWEU, 2016).

Diante da análise da evidenciação ambiental, contribui-se para a literatura de gestão ambiental, bem como com a contabilidade, esta que tem discutido intensamente o papel dos relatórios de sustentabilidade e anuais reportados pelas empresas (QIAN; SCHALTEGGER, 2017).

\subsection{EFLUENTES LÍQUIDOS}

Nos últimos anos houve um crescente interesse em melhorar a sustentabilidade global no que se refere ao tratamento dos efluentes líquidos, com vistas à saúde humana (OZGUN et al., 2014). Desse modo, gerenciar e relatar as emissões, bem como outros aspectos ambientais como os efluentes líquidos, tornou-se cada vez mais popular entre as empresas (QIAN; SCHALTEGGER, 2017).

No que se refere aos efluentes, a Resolução n. 430/2011 designa efluente o termo utilizado para caracterizar os despejos líquidos que são provenientes de diversas atividades ou processos (MINISTÉRIO DO MEIO AMBIENTE; CONSELHO NACIONAL DO MEIO AMBIENTE, 2011). O Global Reporting Initiative (2013) apresenta orientações para a divulgação ambiental das empresas em relação aos efluentes. Assim, nos relatórios de sustentabilidade e anuais as empresas que atendem aos requisitos desse relatório divulgam informações sobre o descarte total de água, discriminando por qualidade (método de tratamento), bem como sua destinação, reutilização, metodologias e premissas adotadas por elas no que diz respeito aos efluentes.

O desempenho ambiental das empresas passa a ser divulgado nesses relatórios de sustentabilidade, em que são realizadas evidenciações voluntárias sobre diversas informações, tais como emissões de gases de efeito estufa, produção de resíduos e consumo de energia, efluentes líquidos, entre outros (BRAAM et al., 2016).

Para tanto, a evidenciação ambiental deve incluir questões ambientais, seu impacto no desempenho futuro da empresa, riscos e incertezas, despesas para com a preservação ambiental e políticas significativas sobre as emissões, os efluentes líquidos entre outros fatores (IATRIDIS, 2013).

As crescentes mudanças climáticas são as questões políticas, societárias e empresariais mais debatidas globalmente, e espera-se que com isso a divulgação ambiental continue a aumentar nos relatórios (QIAN; SCHALTEGGER, 2017). Diante 
disso, à medida que a preservação do meio ambiente se torna gradualmente uma questão de grande preocupação da sociedade, necessita-se de legislações mais rigorosas em relação à descarga de efluentes líquidos, bem como de processos mais eficazes para lidar com os diversos poluentes do meio ambiente (BRILLAS; MARTÍNEZ-HUITLE, 2015).

\section{PROCEDIMENTOS METOdOLÓGICOS}

Diante do objetivo de analisar as informações ambientais evidenciadas nos Relatórios de Sustentabilidade e Relatórios Anuais sobre efluentes líquidos das empresas brasileiras listadas no IBrX-100 da BM\&FBovespa, realizou-se uma pesquisa descritiva, documental e com abordagem quantitativa.

A população da pesquisa compreende todas as empresas pertencentes ao Índice Brasil 100 (IBrX-100) listadas na BM\&FBovespa, compreendendo 100 companhias. Optou-se por essas empresas em razão do fato de ser um índice de preços que mede o retorno de uma carteira teórica composta por 100 ações mais negociadas na Bovespa em termos de número de negócios e volume financeiro (BM\&FBOVESPA, 2014). Contudo, em decorrência de as empresas Bradesco, Klabin e Oi estarem duplicadas, a amostra do estudo foi composta por 97 dessas empresas listadas na Bolsa de Valores de São Paulo, pertencentes ao Índice IBrX-100.

Foram baixados os Relatórios Anuais e de Sustentabilidade diretamente no sítio das empresas pertencentes à amostra, e, nesses relatórios, verificou-se o aspecto efluentes líquidos, seus critérios e subcritérios de acordo com as diretrizes do Global Reporting Initiative (GRI) de 2013. Elaborou-se uma planilha eletrônica de Excel, na qual foi preenchido o nível de cada critério e subcritério analisado de cada empresa.

Vale destacar que esses critérios e subcritérios apresentam diferentes escalas ordinais para expressar ordem entre os níveis, conforme o desempenho de cada critério, o que permite a atribuição de até oito níveis. Salienta-se que os níveis, ou seja, escalas, foram criados a partir da interpretação de todas as informações apresentadas sobre efluentes líquidos nas diretrizes do GRI de 2013.

Ressalta-se que a importância dos níveis é representada a partir das cores vermelho, amarelo e verde, sendo que a cor vermelha é considerada um nível comprometedor; já a cor verde um nível excelente de divulgação para as empresas. Para facilitar o entendimento, a Tabela 1 apresenta a descrição dos critérios e subcritérios do aspecto efluentes líquidos e sua devida mensuração: 
Análise das informações ambientais evidenciadas nos relatórios de sustentabilidade...

Tabela 1 - Descrição e mensuração dos critérios e subcritérios do aspecto efluentes líquidos

\begin{tabular}{|c|c|c|c|c|c|c|c|c|c|}
\hline \multirow{2}{*}{$\begin{array}{c}\begin{array}{c}\text { Aspecto - Critérios e } \\
\text { subcritérios }\end{array} \\
1 \text { EFLUENTES }\end{array}$} & \multirow[t]{2}{*}{ Descrição } & \multicolumn{8}{|c|}{$\begin{array}{c}\text { Mensuração } \\
\text { Escala - Níveis }\end{array}$} \\
\hline & & N1 & N2 & N3 & N4 & N5 & N6 & N7 & N8 \\
\hline 1.1 Tipo de informação & $\begin{array}{l}\text { Qual o tipo de in- } \\
\text { formação prestada? } \\
\text { Nada (N), Descriti- } \\
\text { va (D), Monetária } \\
\text { (M), Quantitativa } \\
\text { (Q). }\end{array}$ & $\mathrm{N}$ & $\mathrm{D}$ & M & Q & $\mathrm{D} / \mathrm{M}$ & $\mathrm{D} / \mathrm{Q}$ & $\mathrm{Q} / \mathrm{M}$ & $\begin{array}{l}\mathrm{D} / \\
\mathrm{Q} / \mathrm{M}\end{array}$ \\
\hline \multicolumn{10}{|l|}{ 1.2 Tratamento } \\
\hline 1.2.1 \% Tratado & $\begin{array}{l}\text { \% de água desti- } \\
\text { nada para descarte } \\
\text { que foi tratada no } \\
\text { último ano. }\end{array}$ & $0 \%$ & $25 \%$ & $50 \%$ & $75 \%$ & $100 \%$ & & & \\
\hline $\begin{array}{l}\text { 1.2.2 Método de trata- } \\
\text { mento }\end{array}$ & $\begin{array}{l}\text { Relata o método de } \\
\text { tratamento utiliza- } \\
\text { do para efluentes } \\
\text { líquidos? Não (N), } \\
\text { Sim (S). }\end{array}$ & $\mathrm{N}$ & $\mathrm{S}$ & & & & & & \\
\hline 1.3 Metas anuais & $\begin{array}{l}\text { \% de metas de re- } \\
\text { dução de efluentes } \\
\text { do ano anterior que } \\
\text { foram atendidas no } \\
\text { último ano. }\end{array}$ & $0 \%$ & $25 \%$ & $50 \%$ & $75 \%$ & $100 \%$ & & & \\
\hline
\end{tabular}

De acordo com a Tabela 1, o aspecto efluentes líquidos apresenta-se dividido em três critérios (tipo de informação, tratamento e metas anuais), sendo que o tratamento se subdivide em outros dois subcritérios (percentual tratado e método de tratamento). O primeiro critério apresenta oito níveis (N) distintos e vai do $\mathrm{N} 1$ ao N8, em que N1 representa nenhuma informação (NADA), N2 informação Descritiva (D), N3 Monetária (M), N4 Quantitativa (Q), N5 Descritiva e Monetária (D/M), N6 Descritiva e Quantitativa (D/Q), N7 Quantitativa e Monetária (Q/M) e N8 Descritiva, Quantitativa e Monetária (D/Q/M).

O critério tratamento apresenta o subcritério percentual tratado, no qual se busca identificar o percentual de água destinada para descarte que foi tratada no último ano, e este está dividido em cinco níveis (N1 a N5). N1 representa um percentual de (0\%), N2 (25\%), N3 (50\%), N4 (75\%) e N5 (100\%). A partir do método de tratamento busca-se verificar se as empresas relatam o método de tratamento utilizado para efluentes líquidos ou não, isto é, (N1 e N2). Por fim, por meio das metas anuais tem-se o objetivo de verificar o percentual de metas de redução de efluentes líquidos 
do ano anterior que foi atendido no último ano, e a escala foi de N1 a N5, sendo N1 igual a $0 \%$ e N5 igual a $100 \%$.

Em relação ao período, visto que a publicação dos relatórios, tanto Relatório Anual (RA) quanto Relatório de Sustentabilidade (RS) ocorre com mais frequência nas empresas analisadas nos últimos anos, principalmente o RS, neste estudo foi analisado o período de 2010 a 2013. Destaca-se que a coleta de dados, ou seja, dos relatórios analisados foi realizada em março e abril de 2014, referente ao período de 2010 a 2012, e em outubro e novembro de 2014 foram baixados os relatórios do ano 2013. Vale salientar que a planilha foi alimentada a partir dos níveis verificados para cada empresa da amostra, em cada ano analisado e referente a cada relatório (RS e RA) de forma individual.

Para a realização da análise dos dados foi utilizada a entropia da informação, na qual se obteve um peso, este utilizado em seguida para a aplicação do método Simple Additive Weighting ( $S A W$ ), obtendo, dessa forma, um ranking para os dados sobre efluentes líquidos apresentados pelas empresas nos seus Relatórios Anuais, e outro ranking apresentando a classificação das empresas a partir do que evidenciaram nos Relatórios de Sustentabilidade nos quatro anos analisados. Após foi realizada a correlação de Spearman para o resultado obtido por meio do ranking do Relatório Anual, outra correlação para os anos analisados do Relatório de Sustentabilidade, e, por fim, uma correlação entre o Relatório Anual e o Relatório de Sustentabilidade para os anos analisados. Para a aplicação do teste da correlação de Spearman foi utilizado o software Statistical Package for the Social Sciences (SPSS).

\section{ANÁLISE DOS DADOS}

Nesta seção apresenta-se inicialmente a evolução da evidenciação sobre efluentes líquidos nos Relatórios Anuais e de Sustentabilidade por meio de gráficos, mostrando o peso da informação de cada critério e subcritério analisado. Por meio desses pesos se obteve o grau de evidenciação dos impactos ambientais sobre efluentes líquidos das empresas analisadas, que foi apresentado por meio de dois rankings. O primeiro foi elaborado com base nas informações que as empresas evidenciaram em seus Relatórios Anuais, já o segundo diz respeito às informações divulgadas nos Relatórios de Sustentabilidade dos quatro anos analisados. Na sequência, para verificar se houve alterações significativas nas posições dos rankings, nos quatro anos analisados, aplicou-se a correlação de Spearman. No Gráfico 1 apresenta-se a evolução da evidenciação sobre os efluentes líquidos nos Relatórios Anuais: 
Gráfico 1 - Evolução da evidenciação sobre os efluentes líquidos nos Relatórios Anuais

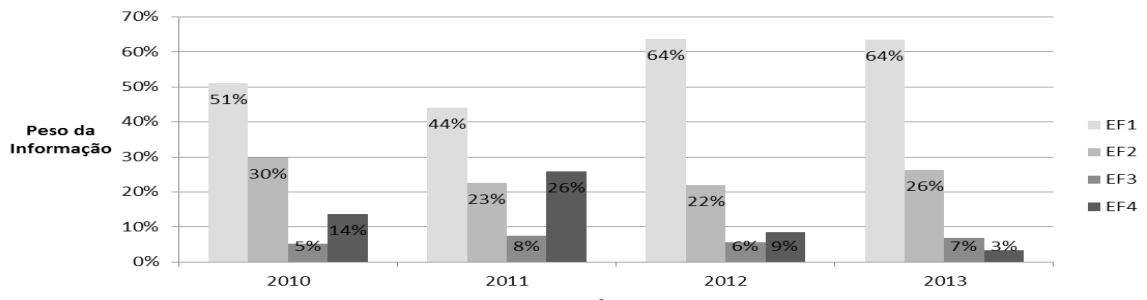

Fonte: os autores.

Conforme o Gráfico 1, percebe-se que entre os critérios e subcritérios analisados, o que mais influencia na evidenciação ambiental sobre efluentes líquidos é o tipo de informação (EF1) divulgada pelas empresas analisadas, visto que esse critério apresentou no ano 2010 51\% de influência, em 2011 decaiu para 44\% e, em 2012 e 2013 obteve os melhores resultados, ou seja, 64\%. Na sequência, o subcritério que se destacou foi o percentual tratado (EF2) e após, as metas anuais. Por fim, o subcritério que apresentou menor influência foi o método de tratamento (EF3), isto é, relata-se ou não o método de tratamento utilizado para efluentes, visto que sobre esse critério houve pouca diferença de uma empresa para a outra nos níveis apresentados. Na sequência apresenta-se o Gráfico 2 que demonstra a evolução da evidenciação sobre os efluentes líquidos nos Relatórios de Sustentabilidade.

Gráfico 2 - Evolução da evidenciação sobre os efluentes líquidos nos Relatórios de Sustentabilidade

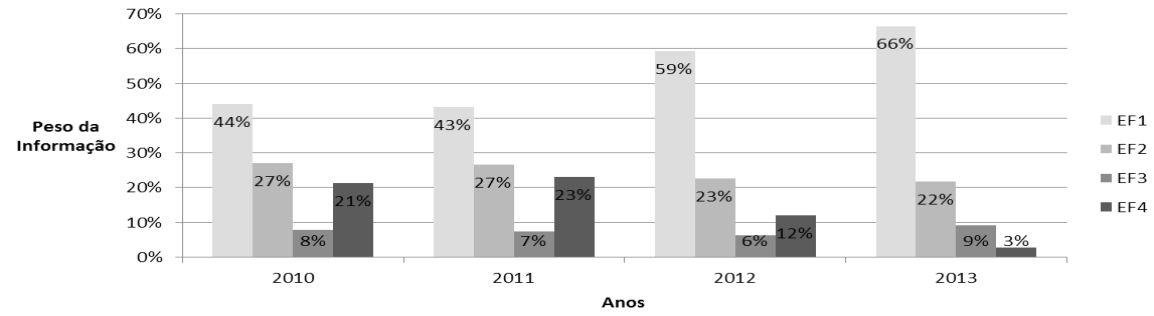

Fonte: os autores.

De acordo com o Gráfico 2, nota-se que o mesmo cenário verificado nos Relatórios Anuais ocorreu nos Relatórios de Sustentabilidade, pois, entre os critérios e subcritérios analisados, o que mais influencia na evidenciação ambiental sobre efluentes é novamente o tipo de informação (EF1). Contudo, diferente da evolução desse critério nos Relatórios Anuais das empresas analisadas, que em 2012 e 2013 apresentou o mesmo percentual, nos Relatórios de Sustentabilidade teve um peso maior da 
informação do ano 2012 para 2013, isto é, de 59\% para 66\%, respectivamente. Ainda, o subcritério que posteriormente apresentou a segunda maior influência na evidenciação sobre efluentes líquidos foi o percentual tratado (EF2), que vai de $0 \%$ a 100\%, (N1-N5). Após, as metas anuais (EF4), que vão também de 0\% a 100\%, e, por fim, o subcritério método de tratamento (EF3), que apresentou a menor influência novamente quando comparado ao Relatório Anual.

Esses resultados referentes aos Relatórios Anuais e de Sustentabilidade demonstram que as empresas apresentam maiores diferenças em relação ao critério tipo de informação, que vai de nenhuma informação (N1) à informação descritiva, quantitativa e monetária (N8). Contudo, em relação ao subcritério método de tratamento (EF3), verificou-se que a maioria das empresas, em seus relatórios, não apresentava o método utilizado para o tratamento dos efluentes líquidos, o que denota que as empresas analisadas deveriam divulgar essa informação aos interessados para atraírem mais investidores e melhorarem a sua imagem perante a sociedade.

Said, Omar e Abdullah (2013) ressaltam que mesmo que os relatórios sejam uma prática sempre mais importante, a qualidade e o tipo de informações apresentados pelas empresas nesses relatórios nem sempre são satisfatórios.

Por meio do Quadro 1 apresenta-se o ranking geral contendo a classificação das 10 empresas com maior evidenciação dos impactos ambientais sobre efluentes líquidos divulgados nos Relatórios Anuais:

Quadro 2 - Ranking geral de evidenciação dos impactos ambientais sobre efluentes líquidos no RA

\begin{tabular}{|c|c|c|c|c|}
\hline \multirow{2}{*}{ Posição } & \multicolumn{4}{|c|}{ Empresas } \\
\hline & 2010 & 2011 & 2012 & 2013 \\
\hline 1 & BRF - Brasil Foods & Ambev & BRF - Brasil Foods & Eletrobras \\
\hline 2 & Ambev & Duratex & Marfrig & Souza Cruz \\
\hline 3 & Copel & Embraer & JBS & Weg \\
\hline 4 & Souza Cruz & BRF - Brasil Foods & Braskem & JBS \\
\hline 5 & Duratex & BM\&FBovespa & Duratex & Marfrig \\
\hline 6 & Itausa & Itausa & Estácio Part. & Braskem \\
\hline 7 & Banco do Brasil & CPFL Energia & CCR & Cemig \\
\hline 8 & Ecorodovias & Energias BR & Cemig & Embraer \\
\hline 9 & CPFL Energia & Copasa & Eletrobras & CPFL Energia \\
\hline 10 & Sid Nacional & Copel & Embraer & Hypermarcas \\
\hline
\end{tabular}

Fonte: os autores.

De acordo com os dados apresentados no Quadro 2, nota-se que a empresa BRF - Brasil Foods e a empresa Duratex são as que se destacaram em pelo menos três dos quatro anos analisados no ranking das 10 empresas que mais evidenciaram sobre 
efluentes líquidos. A empresa BRF - Brasil Foods ocupou a primeira posição no ranking no ano 2010, decaindo para a quarta em 2011 e voltou como primeira no ano 2012.

A partir da verificação do nível de evidenciação divulgado para cada critério e subcritério sobre o aspecto efluentes líquidos, contatou-se que essa empresa BRF Brasil Foods, no ano 2010 e 2012, apresentou informações descritivas e quantitativas quanto ao tipo de informação. Em relação ao percentual tratado, apresentou que 100\% da água destinada para descarte foi tratada no último ano. Sobre esse resultado, verificou-se no Relatório Anual de 2012 que a empresa evidencia, na maioria dos casos, que a água captada é devolvida após o tratamento de efluentes. Assim, a qualidade dessa água que é descartada, em muitos casos, é superior à água do próprio rio.

Além disso, possui método de tratamento para os efluentes líquidos e metas anuais de $100 \%$ de redução de efluentes do ano anterior que foram atendidas no último ano. O motivo de essa empresa ter decaído da primeira para a quarta posição em 2011 ocorreu em razão de ter divulgado apenas informações descritivas, ter apresentado um percentual de $75 \%$ da água que é destinada para descarte, e possuir metas anuais de $75 \%$ de redução de efluentes do ano anterior que foram atendidas no último ano. Contudo, no ano 2013 essa empresa não consta entre as 10 primeiras colocadas no ranking. Isso ocorreu em decorrência do fato de esta não apresentar seu Relatório Anual no ano 2013, quando da realização da coleta dos dados.

A Duratex foi outra empresa que se destacou em pelo menos três dos quatro anos analisados no ranking de evidenciação dos impactos ambientais sobre efluentes líquidos do Relatório Anual, sendo que em 2010 e 2012 constava na quinta posição e, no ano 2011, subiu para a segunda colocação.

Salienta-se que ao verificar o Relatório Anual de 2011 da empresa, identificou-se que a companhia investiu $\mathrm{R} \$ 26,7$ milhões em proteção ambiental e, desse valor, R\$ 8,8 milhões foram destinados para o tratamento de efluentes. Além disso, a Duratex trata seus efluentes de acordo com a legislação ambiental. O descarte segue os padrões estabelecidos pela Resolução Conama n. 357/2005. Ainda, a Companhia investe em Estações de Tratamento de Efluentes (ETEs). Nesse mesmo ano a geração total de efluentes foi de 3.592.506,10 $\mathrm{m}^{3}$, e, desse total, 65\% foram descartados em campos de irrigação para produzir gramíneas que são utilizadas como biomassa na geração de energia térmica.

Entretanto, em 2013 a Duratex apresentou menos informações sobre efluentes líquidos em seu Relatório Anual, e, por esse motivo, não consta entre as 10 empresas mais bem colocadas no ranking. Diante disso, salienta-se que as empresas BRF - Brasil Foods e Duratex foram as que mais se destacaram no ranking, ou seja, apresenta- 
ram níveis mais elevados que as demais empresas no que se refere à evidenciação dos impactos ambientais sobre efluentes líquidos, demonstrando que se preocupam com o meio ambiente. Nesse sentido, Clarkson et al. (2013) destacam que a divulgação ambiental de forma voluntária e transparente aumenta ainda mais o valor da empresa.

Ressalta-se ainda a empresa Ambev, que no ano 2010 estava na segunda posição e no ano 2011 passou a liderar o ranking. Já nos anos 2012 e 2013 a empresa não constava entre as 10 primeiras, visto que não divulgou seu Relatório Anual. A empresa Souza Cruz merece destaque, pois no ano 2010 era a quarta colocada e em 2013 passou a ser a segunda posicionada no ranking. Nos anos 2011 e 2012 apresentou informações sobre efluentes líquidos, porém, com níveis inferiores às demais empresas analisadas.

Outras empresas que se destacaram em decorrência de constarem em dois dos quatro anos analisados entre as 10 primeiras empresas que mais evidenciam informações sobre efluentes líquidos são as seguintes: Copel, Itausa, JBS, Cemig, Eletrobras, CPFL Energia e Embraer. A empresa Eletrobras liderou o ranking em 2013, visto que foi a única que divulgou informações descritivas, quantitativas e monetárias nesse ano sobre efluentes líquidos. Além do mais, evidenciou um percentual de 100\% de tratamento da água para descarte, e relatou o método de tratamento utilizado para os efluentes.

A partir do Quadro 3 apresenta-se o ranking geral de evidenciação dos impactos ambientais sobre efluentes líquidos, de acordo com o que foi divulgado pelas empresas em seus Relatórios de Sustentabilidade nos quatro anos analisados:

Quadro 3 - Ranking geral de evidenciação dos impactos ambientais sobre efluentes líquidos no RS

\begin{tabular}{|c|c|c|c|c|}
\hline \multirow{2}{*}{ Posição } & \multicolumn{4}{|c|}{ Empresas } \\
\hline & 2010 & 2011 & 2012 & 2013 \\
\hline 1 & BRF - Brasil Foods & BRF - Brasil Foods & BRF - Brasil Foods & Eletrobras \\
\hline 2 & Ambev & Eletropaulo & Fibria & JBS \\
\hline 3 & Fibria & Fibria & Klabin & Fibria \\
\hline 4 & Copel & Cemig & Suzano Papel & Braskem \\
\hline 5 & Petrobras & Klabin & Randon Part. & Cemig \\
\hline 6 & Eletropaulo & AES Tietê & JBS & Cosan \\
\hline 7 & Cemig & Petrobras & Braskem & Marcopolo \\
\hline 8 & Duratex & Duratex & Duratex & Petrobras \\
\hline 9 & Rossi Resid. & Natura & Natura & Sabesp \\
\hline 10 & Tractebel & Marcopolo & Marcopolo & Klabin \\
\hline
\end{tabular}


Por meio do Quadro 3 se nota que a empresa Fibria se destacou entre as 10 primeiras posicionadas no ranking nos quatro anos analisados, visto que permaneceu na segunda e terceira posição. Ainda, as empresas BRF - Brasil Foods, Duratex, Cemig, Klabin, Petrobras e Marcopolo ficaram entre as 10 melhores colocadas no ranking de evidenciação dos impactos ambientais sobre efluentes em três dos quatro anos analisados. Por fim, outras empresas que vale destacar são Eletropaulo, JBS, Braskem e Natura pelo fato de estarem entre as que mais evidenciaram informações sobre efluentes líquidos em dois dos quatro anos analisados.

A empresa Fibria ocupou a terceira posição nos anos 2010, 2011 e 2013. Já em 2012 passou para a segunda colocação no ranking, ou seja, melhorou sua posição, contudo, isso não se deve ao fato de ter apresentado mais informações sobre efluentes líquidos do que nos outros anos analisados, mas pelo fato de as outras empresas terem apresentado informações com níveis menores.

De acordo com Said, Omar e Abdullah (2013), quanto mais a empresa participar de atividades relacionadas ao meio ambiente, maior será sua evidenciação. Além disso, Rosa et al. (2014) salientam que a evidenciação ambiental pode ser um meio ou então um conjunto de meios utilizado pelas empresas para expor aos seus stakeholders suas práticas ambientais, e serve como ferramenta de tomada de decisões aos interessados nessas informações.

Destaca-se também a BRF - Brasil Foods, que liderou o ranking em três anos analisados, de 2010 a 2012. Ressalta-se que em 2013 a empresa não apresentou seu Relatório de Sustentabilidade e por isso não constava entre as 10 empresas mais bem posicionadas no ranking. No Quadro 4 são evidenciados os níveis de evidenciação ambiental sobre efluentes líquidos da empresa BRF - Brasil Foods nos anos analisados:

Quadro 4 - Níveis de evidenciação ambiental sobre efluentes líquidos da Empresa BRF - Brasil Foods

\begin{tabular}{|l|l|l|l|l|l|}
\hline \multicolumn{2}{|c|}{ Efluentes } & \multicolumn{1}{|c|}{$\mathbf{2 0 1 0}$} & \multicolumn{1}{|c|}{$\mathbf{2 0 1 1}$} & \multicolumn{1}{|c|}{$\mathbf{2 0 1 2}$} & \multicolumn{1}{|c|}{$\mathbf{2 0 1 3}$} \\
\hline \multicolumn{2}{|l|}{ Tipo de informação } & N6 & N4 & N6 & - \\
\hline \multirow{3}{*}{ Tratamento } & \% Tratado & N5 & N5 & N5 & - \\
\cline { 2 - 7 } & Método de tiratamento & N2 & N2 & N2 & - \\
\hline Metas anuais & N5 & N5 & N5 & - \\
\hline
\end{tabular}
Fonte: os autores.

Diante dos dados apresentados no Quadro 4, percebe-se que a empresa BRF - Brasil Foods divulgou diferente informação somente no que diz respeito ao tipo de informação apresentado, pois nos anos 2010 e 2012 apresentou informações descritivas e quantitativas (N6) e, em 2011, evidenciou informações quantitativas (N4). Em 
relação ao percentual tratado, apresentou em seus relatórios que a empresa possui 100\% de tratamento da água destinada para descarte e relatou o método de tratamento utilizado para os efluentes líquidos. Além disso, no que diz respeito às metas anuais, atingiu $100 \%$ de redução de efluentes do ano anterior que foram atingidas no último ano, nos três períodos que divulgou informação.

Um dos motivos para essa empresa ter liderado o ranking nos três anos, isto é, 2010, 2011 e 2012, é o fato de a BRF - Brasil Foods ter apresentado o nível máximo para o percentual de tratamento (N1-N5), método de tratamento (N1-N2) e metas anuais (N1-N5). Infere-se que, quanto ao tipo de informação, a empresa poderia, para melhorar sua evidenciação ambiental em relação aos efluentes líquidos, apresentar também em seu Relatório de Sustentabilidade informações descritivas, quantitativas e monetárias (D/ $\mathrm{Q} / \mathrm{M})$, visto que apenas apresentou informações descritivas e quantitativas (D/Q). Diante da preocupação da população com o meio ambiente, as empresas são pressionadas a divulgarem informações, como uma prestação de contas à sociedade (ROSA et al., 2011).

Braam et al. (2016) revelaram, a partir de seu estudo, que os efluentes líquidos desempenham um papel significativo na explicação da variação do nível de divulgação ambiental realizado nos relatórios.

Entende-se a partir dos resultados que, quanto mais informações as empresas divulgam, maior será seu desempenho, até porque, de acordo com os achados do estudo desenvolvido por Iatridis (2013), a evidenciação ambiental das empresas está positivamente associada com o desempenho ambiental delas. Assim, as divulgações ambientais devem ser consideradas de alta qualidade para serem relevantes para as empresas e melhoram as percepções dos investidores (IATRIDIS, 2013).

Com o intuito de verificar a relação existente dos rankings por ano, do Relatório Anual das empresas analisadas, aplicou-se a correlação de Spearman. Além disso, analisou-se a correlação entre os anos (rankings) do Relatório de Sustentabilidade e, por fim, foi realizada outra correlação de Spearman para verificar a relação existente entre os rankings (RA e RS). Por meio da Tabela 1 apresenta-se a correlação de Spearman do Relatório Anual das empresas analisadas nos quatro anos:

Tabela 2 - Correlação de Spearman do Relatório Anual

\begin{tabular}{crrrr}
\hline \multicolumn{1}{l}{ RA } & \multicolumn{1}{c}{$\mathbf{2 0 1 0}$} & $\mathbf{2 0 1 1}$ & $\mathbf{2 0 1 2}$ & \multicolumn{1}{c}{$\mathbf{2 0 1 3}$} \\
\hline 2010 & 1 & $0,772^{* *}$ & $0,447^{* *}$ & $0,438^{* *}$ \\
2011 & $0,772^{* *}$ & 1 & $0,451^{* *}$ & $0,394^{* *}$ \\
2012 & $0,447^{* *}$ & $0,451^{* *}$ & 1 & $0,713^{* *}$ \\
2013 & $0,438^{* *}$ & $0,394^{* *}$ & $0,713^{* *}$ & 1 \\
\hline
\end{tabular}


A partir da Tabela 2 percebe-se que em relação aos Relatórios Anuais das empresas analisadas houve correlação ao nível de $1 \%$ entre todos os anos. O resultado obtido no ranking de 2010 para cada empresa esteve correlacionado com os rankings obtidos nos anos 2011, 2012 e 2013. Entretanto, ressalta-se que houve maior correlação dos rankings obtidos do ano 2010 para 2011, isto é, a correlação foi de 77\%. Isso indica que 2010 a 2011 não houve muita diferença dos níveis de informações divulgados sobre efluentes líquidos das empresas analisadas.

Na Tabela 3 apresenta-se a correlação de Spearman, contudo, dessa vez, para os resultados obtidos no ranking de cada ano dos Relatórios de Sustentabilidades analisados:

Tabela 3 - Correlação de Spearman do Relatório de Sustentabilidade

\begin{tabular}{rrrrr}
\hline \multicolumn{1}{c}{ RS } & \multicolumn{2}{l}{$\mathbf{2 0 1 0}$} & $\mathbf{2 0 1 1}$ & \multicolumn{2}{c}{$\mathbf{2 0 1 2}$} & \multicolumn{1}{c}{$\mathbf{2 0 1 3}$} \\
\hline 2010 & 1 & $0,723^{* *}$ & $0,508^{* *}$ & $0,385^{* *}$ \\
2011 & $0,723^{* *}$ & 1 & $0,769 * *$ & $0,551^{* *}$ \\
2012 & $0,508^{* *}$ & $0,769^{* *}$ & 1 & $0,719^{* *}$ \\
2013 & $0,385^{* *}$ & $0,551^{* *}$ & $0,719^{* *}$ & 1 \\
\hline
\end{tabular}

Fonte: os autores.

Nota: **A correlação é significativa no nível $1 \%$.

Por meio da Tabela 3 é possível verificar que, no que diz respeito aos resultados obtidos nos quatro anos analisados sobre os Relatórios de Sustentabilidade, o ano 2011 novamente apresentou maior correlação com o ranking obtido no ano 2010. Porém, dessa vez, a correlação entre os resultados de 2010 e 2013 ficou menor que a obtida no ranking dos Relatórios Anuais analisados. Entende-se que a correlação entre o ranking de 2010 para o de 2013 foi baixa, visto que as informações divulgadas nos Relatórios de Sustentabilidade sobre efluentes foram diferentes nos dois anos para as empresas analisadas.

A Tabela 4 evidencia a correlação de Spearman entre os rankings dos quatro anos obtidos por meio da análise dos critérios e subcritérios nos Relatórios Anuais e os rankings dos anos analisados, obtidos por meio da análise desses mesmos critérios e subcritérios nos Relatórios de Sustentabilidade: 
Tabela 4 - Correlação de Spearman entre o Relatório Anual e o Relatório de Sustentabilidade

\begin{tabular}{|c|c|c|c|c|c|c|c|c|}
\hline & \multicolumn{4}{|c|}{ Relatório Anual } & \multicolumn{4}{|c|}{ Relatório de Sustentabilidade } \\
\hline & 2010 & 2011 & 2012 & 2013 & 2010 & 2011 & 2012 & 2013 \\
\hline RA 2010 & 1 & $0,772 * *$ & $0,447^{* *}$ & $0,438 * *$ & $0,376 * *$ & $0,248 *$ & $0,286^{* *}$ & $0,323^{* *}$ \\
\hline RA 2011 & $0,772 * *$ & 1 & $0,451^{* *}$ & $0,394 * *$ & $0,375^{* *}$ & $0,201 *$ & 0,172 & $0,207^{*}$ \\
\hline RA 2012 & $0,447 * *$ & $0,451 * *$ & 1 & $0,713 * *$ & $0,250 *$ & $0,281 * *$ & $0,386 * *$ & $0,352 * *$ \\
\hline RA 2013 & $0,438 * *$ & $0,394^{* *}$ & $0,713 * *$ & 1 & $0,214^{*}$ & $0,330^{* *}$ & $0,377^{* * *}$ & $0,477^{* *}$ \\
\hline RS 2010 & $0,376^{* *}$ & $0,375 * *$ & $0,250 *$ & $0,214^{*}$ & 1 & $0,723 * *$ & $0,528 * *$ & $0,385^{* *}$ \\
\hline RS 2011 & $0,249 *$ & $0,201 *$ & $0,281^{* *}$ & $0,330 * *$ & $0,723 * *$ & 1 & $0,769 * *$ & $0,551 * *$ \\
\hline RS 2012 & $0,286^{* *}$ & 0,172 & $0,386 * *$ & $0,377^{*}$ & $0,508 * *$ & $0,769 * *$ & 1 & $0,719^{* *}$ \\
\hline RS 2013 & $0,323 * *$ & $0,207^{*}$ & $0,352 * *$ & $0,477 * *$ & $0,385 * *$ & $0,551 * *$ & $0,719 * *$ & 1 \\
\hline
\end{tabular}

Fonte: os autores.

Notas: **A correlação é significativa no nível $1 \%$.

*A correlação é significativa no nível 5\%.

De acordo com a Tabela 4, na correlação de Spearman entre os anos analisados e os relatórios verificados, nota-se que o resultado obtido em relação aos rankings dos Relatórios Anuais de 2010 possui correlação nos níveis de 1\% e 5\%. O resultado por meio da verificação dos Relatórios Anuais de 2010 apresentou uma correlação alta com o RA de 2011, visto que foi de 77\%. Ainda, constatou-se uma correlação baixa com os Relatórios de Sustentabilidade, sendo que o ano que apresentou maior correlação com o RA foi o ano 2010, no qual se obteve um percentual de 37,6\%, na sequência os anos 2013, 2012 e 2011. Isso demonstra que as informações apresentadas nos Relatórios Anuais e de Sustentabilidade sobre efluentes líquidos são diferentes de um relatório para o outro das empresas analisadas.

Nesse sentido, os achados de Vogt et al. (2017) corroboram, tendo em vista que verificaram que não há um padrão de divulgação nos relatórios das empresas em relação à divulgação das informações ambientais.

\section{CONSIDERAÇÕES FINAIS}

Neste estudo analisou-se, entre um conjunto de critérios e subcritérios ambientais, as informações ambientais evidenciadas nos Relatórios de Sustentabilidade e Relatórios Anuais sobre efluentes líquidos das empresas brasileiras listadas no IBrX100 da BM\&FBovespa. Para a consecução do objetivo proposto, realizou-se uma pesquisa descritiva, com abordagem quantitativa, por meio de análise documental. 
Os resultados revelaram que em relação ao peso da informação sobre os critérios e subcritérios analisados de efluentes líquidos, as empresas divulgam praticamente as mesmas informações nos anos analisados a respeito do tipo de informação, visto que esse critério apresentou a maior influência na evidenciação sobre efluentes em ambos os relatórios. Contudo, a maioria das empresas analisadas não divulga informações sobre o método de tratamento em seus relatórios, ou seja, não possui método de tratamento para os efluentes líquidos. Para tanto, as empresas analisadas devem se preocupar mais com essas informações e apresentá-las em seus relatórios, para que possam melhorar sua imagem perante a sociedade.

Além disso, os resultados demonstraram, no que se refere ao ranking geral de evidenciação dos impactos ambientais sobre efluentes líquidos nos Relatórios Anuais, que as empresas que mais se destacaram entre as 10 primeiras posicionadas no ranking dos anos analisados foram BRF - Brasil Foods e Duratex, em três dos quatro anos analisados, seguidas das Empresas Copel, Itausa, JBS, Cemig, Eletrobras, CPFL Energia e Embraer, as quais se destacaram em dois dos quatro anos analisados.

Já em relação ao ranking obtido pela evidenciação sobre efluentes nos Relatórios de Sustentabilidade, tem-se que as Empresas Fibria e novamente a BRF - Brasil Foods foram as que mais evidenciaram informações nos anos analisados e ficaram mais bem posicionadas no ranking. Além destas, tem-se as empresas Duratex, Cemig, Klabin, Petrobras e Marcopolo que também se destacaram entre as 10 empresas que mais evidenciaram informações sobre efluentes líquidos nos anos analisados.

A partir desses resultados pode-se inferir que mesmo as empresas tendo se destacado nos rankings obtidos por meio da análise dos Relatórios Anuais e de Sustentabilidade, elas precisam melhorar sua evidenciação ambiental, pois muitas informações ainda não estão sendo evidenciadas, como, por exemplo, em relação ao tipo de informação, a informação monetária. Já no que diz respeito ao percentual tratado, tem-se um número baixo de empresas que evidencia que está tratando 100\% seus efluentes. Em relação ao método de tratamento, poucas empresas relatam que possuem método para isso. Da mesma forma, sobre as metas anuais, poucas empresas apresentaram o percentual de metas, e das que divulgaram, poucas atingiram o nível máximo de evidenciação, ou seja, 100\% de metas de redução.

No que se refere à correlação, os resultados evidenciaram que houve correlação no nível de 1\% e 5\% entre os rankings dos Relatórios Anuais e de Sustentabilidade, sendo que o Relatório Anual 2010 teve maior correlação com o ranking (Relatório Anual) de 2011. Quando verificados os rankings obtidos a partir da análise dos Relatórios Anuais com os de Sustentabilidade, obteve-se que o ano 2010 esteve 
mais correlacionado com o mesmo ano do ranking do Relatório de Sustentabilidade. Infere-se, a partir disso, que as informações evidenciadas sobre efluentes nos relatórios são diferentes de um ano analisado para o outro.

Conclui-se que as informações ambientais evidenciadas sobre efluentes líquidos das empresas brasileiras deveriam ser mais divulgadas nos Relatórios Anuais e de Sustentabilidade, visto que muitas empresas não apresentaram nenhuma informação sobre os critérios e subcritérios analisados. Outras até evidenciaram, porém, em níveis menores que o considerado excelente de acordo com o GRI. Diante disso, entende-se que as empresas brasileiras analisadas devam se preocupar mais com a evidenciação ambiental sobre efluentes líquidos para, assim, melhorar sua imagem perante a sociedade, atraindo mais investidores.

Esta pesquisa contribui para a literatura, visto que muitas empresas deixam de divulgar dados ambientais sobre os efluentes líquidos para a sociedade e ações frente ao meio ambiente que aumentam o valor da empresa. Se divulgassem mais informações, o Governo também poderia auxiliar na busca de soluções preventivas para reduzir os problemas em relação ao meio ambiente.

Nesta pesquisa apresentam-se algumas limitações, visto que não há uma uniformidade entre os Relatórios Anuais e os Relatórios de Sustentabilidade disponibilizados pelas empresas analisadas, e os resultados obtidos não podem ser generalizados, visto que foram analisadas apenas as empresas brasileiras listadas no IBrX-100. Como recomendações para pesquisas futuras, sugere-se a análise sobre efluentes líquidos de todas as empresas brasileiras, bem como de empresas de outros países, e a verificação de outros aspectos relevantes relacionados ao meio ambiente que constam no GRI.

\section{REFERÊNCIAS}

ABURAYA, R. K. The relationship between corporate governance and environmental disclosure: UK evidence. 2012. 460 p. Tese (Doutorado em Filosofia em Contabilidade)-Durham University, Inglaterra, 2012.

ALBERTINI, E. A descriptive analysis of environmental disclosure: A longitudinal study of French companies. Journal of Business Ethics, v. 121, i. 2, p. 233-254, 2013.

BEUREN, I. M.; NASCIMENTO, S. do; ROCHA, I. Nível de evidenciação ambiental e desempenho econômico de empresas: aplicando a análise envoltória de dados. Future Studies Research Journal: Trends and Strategy, v. 5, i. 1, p. 198-227, 2013. 
BM\&FBOVESPA - Bolsa de Valores e Mercadorias de São Paulo. Índice Brasil 100 - IBrX-100. 2014. Disponível em: <http://www.bmfbovespa.com.br/indices/ ResumoIndice.aspx?Indice=IBrX\&Idioma=pt-br>. Acesso em: 03 fev. 2015.

BRAAM, G. J. M. et al. Determinants of corporate environmental reporting: the importance of environmental performance and assurance. Journal of Cleaner Production, v. 129, i. 1, p. 724-734, 2016.

BRILLAS, E.; MARTÍNEZ-HUITLE, C. A. Decontamination of wastewaters containing synthetic organic dyes by electrochemical methods. An updated review. Applied Catalysis B: Environmental, v. 166, p. 603-643, 2015.

CHO, C. H.; PATTEN, D. M. Green accounting: Reflections from a CSR and environmental disclosure perspective. Critical Perspectives on Accounting, v. 24, i. 6, p. 443-447, 2013.

CLARKSON, P. M. et al. The relevance of environmental disclosures: Are such disclosures incrementally informative? Journal of Accounting and Public Policy, v. 32, i. 5, p. 410-431, 2013.

GLOBAL RePORTING INITIATIVE. Princípios para Relato e Conteúdos Padrão. 2013.

IATRIDIS, G. E. Environmental disclosure quality: Evidence on environmental performance, corporate governance and value relevance. Emerging Markets Review, v. 14, i. 1, p. 55-75, 2013.

LU, Y.; ABEYSEKERA, I. Stakeholders' power, corporate characteristics, and social and environmental disclosure: evidence from China. Journal of Cleaner Production, v. 64, i. 1, p. 426-436, 2014.

MACÊDO, F. F. R. R. et al. Evidenciação ambiental voluntária de companhias listadas no índice carbono eficiente da BM\&FBovespa. RACE-Revista de Administração, Contabilidade e Economia, v. 13, i. 1, p. 329-352, 2014.

MATHUVA, D. M.; KIWEU, J. M. Cooperative social and environmental disclosure and financial performance of savings and credit cooperatives in Kenya. Advances in Accounting, v. 35, i. 1, p. 197-206, 2016. 
MENG, X. H. et al. The relationship between corporate environmental performance and environmental disclosure: An empirical study in China. Journal of Environmental Management, v. 145, i. 1, p. 357-367, 2014.

MINISTÉRIO DO MEIO AMBIENTE; CONSELHO NACIONAL DO MEIO AMBIENTE. Resolução n. 357, de 17 de março de 2005. Dispõe sobre a classificação dos corpos de água e diretrizes ambientais para o seu enquadramento, bem como estabelece as condições e padrões de lançamento de efluentes, e dá outras providências. Disponível em: <http://www.mma.gov.br/port/conama/legiabre.cfm?codlegi=459> . Acesso em: 03 fev. 2015.

MINISTÉRIO DO MEIO AMBIENTE; CONSELHO NACIONAL DO MEIO AMBIENTE. Resolução n. 430, de 13 de maio de 2011. Dispõe sobre as condições e padrões de lançamento de efluentes. 2011. Disponível em: <http://www.mma.gov. br/port/conama/res/res11/propresol_lanceflue_30e31mar11.pdf > . Acesso em: 03 fev. 2015.

NOR, N. M. et al. The effects of environmental disclosure on financial performance in malaysia. Procedia Economics and Finance, v. 35, i. 1, p. 117-126, 2016.

OLIVEIRA, A. F. de; MACHADO, D. G.; BEUREN, I. M. Disclosure Ambiental de Empresas de Setores Potencialmente Poluidores Listadas no Índice de Sustentabilidade Empresarial (ISE). Revista de Gestão Social e Ambiental, v. 6, n. 1, p. 20-37, 2012.

OZGUN, H. et al. Impact of Membrane Addition for Effluent Extraction on the Performance and Sludge Characteristics of Upflow Anaerobic Sludge Blanket Reactors Treating Municipal Wastewater. Journal of Membrane Science, v. 479, p. 95-104, 2014.

PEREIRA, F. E.; MORAIS LUZ, J. R. de; CARVALHO, J. R. M. de. Evidenciação das Informações Ambientais das Empresas do Setor de Energia Elétrica do Brasil. Revista Evidenciação Contábil \& Finanças, v. 3, n. 2, p. 60-72, 2015.

QIAN, W.; SCHALTEGGER, S. Revisiting carbon disclosure and performance: Legitimacy and management views. The British Accounting Review, v. 49, i. 4, p. 365-379, 2017.

ROSA, F. S. da; ENSSLIN, S. R.; ENSSLIN, L. Evidenciação ambiental: processo estruturado de revisão de literatura sobre avaliação de desempenho da evidenciação ambiental. Sociedade, Contabilidade e Gestão, v. 4, n. 2, p. 24-37, 2009. 
ROSA, F. S. da et al. Analysis of the determinants of disclosure of environmental impacts of Brazilian companies. Global Advanced Research Journals, v. 3, i. 6, p. 249-266, 2014.

ROSA, F. S. da et al. Environmental impact management of Brazilian companies: analyzing factors that influence disclosure of waste, emissions, effluents, and other impacts. Journal of Cleaner Production, v. 96, i. 1, p. 148-160, 2015.

ROSA, F. S. da et al. Evidenciação ambiental: estudo comparativo das contribuições teórico-metodológicas de Brasil e Espanha. Revista Universo Contábil, v. 8, n. 1, p. 123-140, 2012.

ROSA, F. S. da et al. Gestão da evidenciação ambiental: um estudo sobre as potencialidades e oportunidades do tema. Engenharia Sanitária Ambiental, v. 16, n. 1, p. 157-166, 2011.

SAID, R.; OMAR, N.; ABDULLAH, W. N. Empirical investigations on boards, business characteristics, human capital and environmental reporting. Social Responsibility Journal, v. 9, i. 4, p. 534-553, 2013.

TIAN, X.-L. et al. Different extent of environmental information disclosure across chinese cities: Contributing factors and correlation with local pollution. Global Environmental Change, v. 39, i. 1, p. 244-257, 2016.

VILLIERS, C. de; LOW, M.; SAMKIN, G. The institutionalisation of mining company sustainability disclosures. Journal of Cleaner Production, p. 1-8, 2014.

VOGT, M. et al. Relationship between determinant factors of disclosure of information on environmental impacts of Brazilian companies. Estudios Gerenciales, v. 33, i. 142, p. 24-38, 2017.

WANG, H.; BERNELL, D. Environmental Disclosure in China: An Examination of the Green Securities Policy. The Journal of Environment \& Development, v. 22, i. 4, p. 339-369, 2013.

ZHENG, S.; KAHN, M. Understanding China’s urban pollution dynamics. Journal of Economic Literature, v. 51, i. 3, p. 731-772, 2013. 


\section{Como citar este artigo:}

\section{ABNT}

VOGT, Mara et al. Análise das informações ambientais evidenciadas nos relatórios de sustentabilidade e relatórios anuais sobre efluentes líquidos das empresas brasileiras. RACE, Revista de Administração, Contabilidade e Economia, Joaçaba: Ed. Unoesc, v. 17, n. 1, p. 55-78, jan./abr. 2018. Disponível em: <http://editora.unoesc. edu.br/index.php/race>. Acesso em: dia/mês/ano.

\section{APA}

Vogt, M., Degenhart, L., Hein, N., \& Rosa, F. S. da. (2018). Análise das informações ambientais evidenciadas nos relatórios de sustentabilidade e relatórios anuais sobre efluentes líquidos das empresas brasileiras. RACE, Revista de Administração, Contabilidade e Economia, 17(1), 55-78. Recuperado em dia/mês/ano, de http://editora. unoesc.edu.br/index.php/race 